\title{
Chapter 13 \\ Supporting Behavioural Entrepreneurs: Using the Biodiversity-Health Relationship to Help Citizens Self-Initiate Sustainability Behaviour
}

\author{
Raymond De Young
}

\begin{abstract}
Techno-industrial societies face biophysical limits and the consequences of disrupting Earth's ecosystems. This creates a new behavioural context with an unmistakable demand: Citizens of such societies must turn from seeking new resources to crafting new living patterns that function well within finite ecosystems. This coming transition is inevitable, but our response is not preordained. Indeed, given the complex, multi-decade-long context, the required pro-environmental behaviours cannot be fully known in advance. Furthermore, the urgency to respond will necessitate that whole clusters of behaviour be adopted; incremental and serial change will not suffice. Thus, a culture of small experiments must be nurtured. The process of change will seriously tax social, emotional and attentional capacities. Thus, priority is placed on emotional stability and clear-headedness, maintaining social relationships while stressed, pro-actively managing behaviour and a willingness to reskill. These aspects of coping share a common foundation: the maintenance of attentional vitality and psychological well-being. Changes also must occur in how pro-environmental behaviours are promoted. We must move beyond interventions that are expert-driven, modest in request, serial in implementation and short-term in horizon. New interventions must create the conditions under which citizens become behavioural entrepreneurs, themselves creating, managing and sharing successful approaches to behaviour change.
\end{abstract}

Keywords Behavioural entrepreneurs $\cdot$ Behavioural aesthetics $\cdot$ Biophysical limits $\cdot$ Behaviour change $\cdot$ Energy descent $\cdot$ Mental vitality

\section{Highlights}

- Biophysical limits and climate disruption have created a new behavioural context.

R. De Young $(\bowtie)$

School for Environment and Sustainability, University of Michigan, Ann Arbor, MI, USA

e-mail: rdeyoung@umich.edu 
- Environmental behaviours needed later this century cannot be fully known in advance.

- Attentional vitality and psychological equipoise are needed for behaviour change.

- Clusters of behaviour must be adopted; serial, incremental change will not suffice.

- Conditions can be created under which citizens become behavioural entrepreneurs.

\subsection{Introduction}

How ever vast were the resources used to create techno-industrial society, they were never limitless. And how ever massive was the waste sink that these societies made out of the atmosphere, it is no longer able to absorb their wastes. Biophysical limits and the consequences of having disrupted the Earth's ecosystems lead to an unmistakable outcome: starting this century, citizens of these societies will consume fewer resources and live more simply. Unfortunately, their current worldviews, goals and behaviours are not prepared for this new reality.

Certainly, it is possible to live at a dramatically lower energy and material flux. Indeed, almost all of human history occurred within a pre-industrial low-energy context, and such an existence is commonplace for much of the current global population. However, the comforts and conveniences of techno-industrial society are unlikely to be possible under the new biophysical context outlined below. Thus, the focus of this chapter is on helping the citizens of such a society weather their inevitable transition to a more frugal existence, and it is the experiences and behaviours of those individuals to whom this chapter will refer.

A decline in resource availability occurring alongside a need to respond to climate disruption will upend life patterns and is not welcomed by reasonable individuals. Nonetheless, this looming reality is as well documented as it is stark. Consider that, near the end of this century, addressing climate disruption alone requires that we produce below a tenth of current greenhouse gas emissions, and probably requires a comparable reduction in consumption of energy and materials. The environmental community has long argued for significant reductions in consumption and emissions, but never have order-of-magnitude changes been envisioned.

Our species' adaptive, entrepreneurial nature suggests that we might respond well to this new reality under certain conditions. The needed changes will place a priority on clear-headedness, the ability to thoughtfully plan and manage behaviour and a willingness to continuously build new competencies. These capacities, in turn, depend on mental well-being (see Part II, this volume). After introducing how the new biophysical context has created a new behavioural context, this chapter suggests how to help people to respond well to this new reality. 


\subsection{New Biophysical Context}

Numerous vulnerabilities have been uncovered within the techno-industrial development approach adopted in many parts of the globe (Meadows et al. 1972, 2004). Tainter (1988) evaluated 11 ways that societies might succumb to constraints and, in the process, identified a new vulnerability. Tainter's concept, the risk of diminishing marginal returns from increasing social complexity, is a social version of the economic principle of diminishing returns. In essence, societies solve the problems they face through an increasing investment in social and/or political complexity. However, this approach eventually becomes too costly to maintain and the society adopting that problem-solving approach becomes unsustainable.

Without providing an exhaustive account of all vulnerabilities, it is nonetheless possible to establish our predicament by considering a basic idea. Like all living systems, techno-industrial civilisation has a metabolism: resources are consumed, work done and waste products discharged. It is sufficient for the purpose here to follow just one of many metabolites, hydrocarbons, starting as a source of energy, consumed in the creation and support of social services and eventually becoming a waste. On the input side, the system vulnerabilities are from limits-to-growth (Jackson and Webster 2016; Turner 2008, 2012), a notion that has lingered on the fringe of environmental discourse. Most reactions to the fact of biophysical limits to material growth have varied within a narrow range between dismissive and derisive. However, an expected end to energy-fueled growth is receiving renewed attention from both ecologists and economists (Bardi 2014, 2011; Daly and Farley 2010; Hall and Day 2009). One aspect of hydrocarbon-based limits-to-growth, that of declining net energy, is particularly troublesome and discussed below. On the output side, the waste involves carbon-based emissions that create the well-documented disruptions to the climate system (Hansen et al. 2017). Taken together, these highlight a radically changed biophysical reality where, as McKibben (2010) contends, the planet onto which we were born has been so altered that it is not the world on which we now live.

\subsubsection{Surplus Energy Decline}

Social systems voraciously consume energy in the course of doing their work. Thus, for social services (e.g. infrastructure, manufacturing, maintenance, provisioning, education, governance, health-care, travel, tourism, entertainment) to continue functioning, there must be a net surplus of energy generated elsewhere. Maintaining a sufficient surplus is becoming increasingly difficult. The issue here has many technical aspects but is also commonsense; it takes energy to get energy and transform it into socially usable forms. Prosperity in techno-industrial society derives from there being a significant surplus available after deducting from the total energy extracted, the amount used to get it (Morgan 2016). One concern that highlights the 
new biophysical context is a decline in energy-returned-on-energy-invested (EROEI), which is one way to measure surplus energy. EROEI was first studied by Odum (1973); it is a foundation of biophysical economics (Cleveland et al. 1984) and energy analysis (Cleveland 2005; Hall 2011, 2012; Hall and Klitgaard 2011), and is proving useful in macroeconomic analysis (Fagnart and Germain 2016). The low-hanging fruit metaphor explains EROEI. Initially, extraction occurs at more attractive locations containing high-quality resources that are easy to extract, process and deliver. Later, resources are found at inhospitable sites, are of lower thermodynamic quality and are harder to recover, refine and transport. Harder here ultimately means consuming ever-greater amounts of energy in order to extract energy. This is a logical pattern - pursue the easiest to get first - but results in a decline over time in surplus energy (Murphy 2014).

Early on, a massive surplus of energy misled us with the false promise of endless physical growth. False because, although it largely went unnoticed, surplus energy was on an unrelenting decline (Hall 2012, 2017; Heinberg and Fridley 2016; Morgan 2016). The minimum EROEI needed to support a techno-industrial society is being explored by Hall and his colleagues (Hall 2011, 2012; Hall et al. 2009; Guilford et al. 2011). In their analysis, it matters enormously what social services are deemed necessary. As the features included in the definition increase, so too does the EROEI ratio needed to support that society. Historically, EROEI was calculated at the energy source - the wellhead - and included only the energy consumed by the hydrocarbon exploration and production industry. In order to make this concept useful for social decision-making, Hall et al. (2009) developed an analysis that accounts for the many indirect energy costs experienced when providing any particular service to society. This is the surplus energy needed by citizens, organisations or communities pursuing their everyday activities and is reported as the extended-EROEI ratio. This research is still maturing but its general conclusions are firm. Declining surplus energy at the societal level is bringing ever closer the day when the resources at our disposal will be insufficient to maintain growth in, and perhaps the full maintenance of, the personal, social and urban systems to which we have become accustomed.

Thus, considering just one aspect of one input to techno-industrial society's metabolism reveals a significant vulnerability. All is well so long as there is a significant surplus of energy. However, over time that surplus is getting smaller.

\subsubsection{Climate Disruption}

Climate disruption, a consequence of the rapacious use of hydrocarbon-based fuels, is empirically established and settled science; the evidence is unequivocal. Profound changes to the earth's thermal patterns are occurring (IPCC 2014) and appear to be accelerating (Herring et al. 2018). Furthermore, what were once worst-case and decades-distant consequences are now taking place (Hansen et al. 2017). There is hope that the Rio/Kyoto/Copenhagen/Cancun/Durban/Doha/Warsaw/Lima/Paris 
negotiating process has finally created a nascent global response. Nevertheless, few people are so optimistic as to believe this response will allow techno-industrial society to continue unchanged or for the planet to return to its preindustrial climate.

Even if the improbable happens (i.e. greenhouse gas emissions are immediately and entirely eliminated) there is enough warming baked into the system to disrupt the climate well into the next century. Apparently, the best to expect is eventually to stabilize the disruption that industrialisation caused. Scenarios that keep atmospheric $\mathrm{CO}_{2}$ concentration levels below $450 \mathrm{ppm}$ by 2100 (essential for keeping global temperature rise below a barely tolerable $2^{\circ} \mathrm{C}$ ) all require quickly initiating and then indefinitely sustaining reductions in emissions (IPCC 2014). Achieving stabilisation at that level requires reductions that are frankly brutal: 40-70\% lower global emission by 2050, with higher percentages required from techno-industrial countries and near zero global emission levels by 2100 . Never before have we contemplated making such a massive reduction and then to maintain, if not deepen, that reduction forever.

The bleak nature of this new biophysical context is not easily contemplated. Thus, persuasively establishing its inevitability should only be done when serving a worthy purpose. The reason for stating this premise is the expectation that we will soon, one way or another, be consuming far fewer resources. The greater purpose in this chapter is to focus our efforts on discovering the conditions necessary to help citizens to pre-familiarise and pre-adapt themselves to this new reality before being forced to do so by biophysical circumstances.

\subsection{New Behavioural Context}

During a historically brief period of material affluence, it has been possible to ignore the biophysical foundation of civilisation. Behavioural scientists could focus on improving physical, mental and social well-being while remaining ignorant of resource constraints. During this time conservation psychology developed effective interventions for promoting environmental stewardship (Clayton 2012; Hamann et al. 2016) and responding to global climate change (Clayton et al. 2015). Recently, however, it has been questioned whether a consumer-focused, fossil-fueled technoindustrial society can ever be made sustainable (Bardi 2011; De Young 2014; Monbiot 2015; Princen 2014; Princen et al. 2002; Turner 2008, 2012).

\subsubsection{A Predicament, Not a Problem}

This new behavioural context cannot be framed as a problem, at least not in the common definition of that word. It is a predicament, an unsolvable situation that will play out over many decades, perhaps through this century and into the next. If it were a problem, we would seek a solution and by applying that solution we would 
return to normal (Greer 2008). In contrast, predicaments have no solution; instead, they must be endured. Society can respond, but even an effective response does not eliminate the predicament. A useful response does not alter but rather accommodates the new situation. This is adaptation in a classic sense: to change behaviour into new forms that better fit a new reality.

If we faced a problem (e.g. emergency, crisis) then we might be advised to weather the storm until we 'get back to normal'. However, even a functional response to a predicament is unlikely to get us back; accommodation is about 'getting to a new normal'. The new behavioural context is also different in another significant way. Responses will need to be broadly applied across one's entire behaviour pattern, then maintained and even expanded throughout a lifetime. Unfortunately, society has little familiarity with the long-drawn-out behavioural planning and management needed to respond in this way. For while we know behaviours adequate for addressing short-term challenges to health and well-being, there exists little guidance for behaviour change necessary for addressing a many decade- or century-long predicament.

\subsubsection{Changing Multiple Behaviours}

Early conservation research focused on promoting one or a small suite of behaviours (Hamilton et al. 2018). We designed interventions to promote household recycling, mass transit use and water conservation (see, for instance, Geller et al. 1982). Most early studies focused on either providing information (e.g. environmental education, enhancing procedural knowledge) or motivation (e.g. economic incentives, token rewards). More recently, the focus has shifted to using social norms (e.g. injunctive norms, declarative norms) and team-based interventions (e.g. eco-teams). However, seldom was the focus on promoting clusters of behaviours. Other research explored not how to promote a specific behaviour, but what we know about people who already practice conservation behaviours. Research on long-term participants in environmental stewardship programs report two consistent motivations: the opportunity to do something meaningful to benefit the environment and the chance to learn something new (Ryan and Grese 2005; Ryan et al. 2001).

Later, Stern and colleagues made sense out of the huge array of available behaviours by suggesting we concentrate on those with the greatest environmental significance (Gardner and Stern 2002; Stern 2000). This logic prioritised high-impact behaviours, those with the highest achievable reduction in carbon emissions or resource consumption. The choice is based not only on a behaviour's technical potential (i.e. degree of impact if adopted) but also upon the social scale of its adoption (i.e. realistic adoption rate across an extended time-scale; Stern 2011).

Unfortunately, this approach still easily defaults to the serial adoption of behaviours given the individual costs and efforts involved (e.g. upgrading heating systems, buying fuel-efficient vehicles). If circumstances allow us to be patient then we benefit from their joint effects over time being significant (see Stern and Wolske's (2017) perspective on Wynes and Nicholas (2017)). Implementation principles are 
being developed that attend to the differences between actions having immediate effects versus reductions that only occur over a decadal time-scale (Wolske and Stern 2018). We are also learning to design interventions that are durable (i.e. the behaviour is maintained long after the intervention has ended; Moore and Boldero 2017) and generalisable (i.e. the effect of an intervention spills over to other contexts and behaviours; Nilsson et al. 2017) both useful features for promoting and sustaining multiple behaviours.

\subsubsection{Cannot Know the Behaviours Needed}

Dietz et al. (2009) highlighted the importance of simultaneously changing multiple behaviours, each selected for their high short-term impact. However, they also predicted that "lifestyle changes may become necessary in the out-years under constrained energy supply or economic growth scenarios" (2009: 18455). This identifies an important concern. Embedded in our current approach is the assumption that we can know, well in advance, the appropriate environmental stewardship behaviours to promote. This prior-knowledge would be essential for the development of the policies, incentives or nudges (Thaler and Sunstein 2008) necessary to direct behaviour. Such knowledge might also be needed for a new behavioural change approach, that of developing boosts that enhance old, or create new, competencies (Hertwig and Grüne-Yanoff 2017). Yet, under the new context posited here, this assumption is not met. There exists only a general outline of required future behaviours, not their details. Indeed, it is nearly impossible to imagine what everyday life might involve after a drastic reduction in surplus energy coupled with accelerating climate disruption.

This behavioural predicament is twofold. We cannot prescribe the specific behaviours that will need adopting decades hence, other than to suggest that they may be very different from what is now familiar. Furthermore, there will be an urgency to respond, which will necessitate the adoption of whole clusters of behaviours; incremental and serial change will no longer suffice.

\subsection{New Form of Intervention}

There is a great difference between green consumerism and a newly emerging pattern of behaviours labeled green citizenship. This difference will become increasingly important as we confront the new behavioural context. Much of our current attention focuses on encouraging green consumerism. It is assumed that by modifying consumer choices it is possible to sustain a techno-industrial society. Green consumerism is fully compatible with efforts to make only incremental changes to techno-industrial society. Within this framework, consumers are treated as fully independent, self-determining and sovereign (Princen 2010; Princen et al. 2002). 
Few, if any, constraints are to be placed on their decision-making, and their consumer choice, once made, is self-justifying and neither to be challenged nor judged. Furthermore, the behaviours promoted must be easily reversible thus preserving the individual's autonomy (Thaler and Sunstein 2008). Green consumerism is also a comfortable approach because it is not a complicated set of behaviours, does not require mentally draining decision-making and it contains the unspoken promise that after achieving an environmentally sustainable state, most of the benefits of modernity will remain. Unfortunately, green consumerism has proven ineffective in curbing collective rates of consumption. Despite greatly improved efficiencies and clever behavioural interventions, society's aggregate energy usage and emissions continue to climb (Dietz et al. 2007; Jackson 2009; Monbiot 2015; Rees 2010).

In contrast, green citizenship is an approach that promotes behaviours based on different motivations and a longer-term time horizon. Recent work suggests that green citizens identify alternate paths of engaging with environmental stewardship that are not limited to the consumptive, product-centric actions defined by green consumerism (Alexander 2011). By moving beyond a consumption focus, green citizens enjoy a broad set of benefits embedded within alternative life patterns. Empirical research reveals that individuals find the pursuit of competence (e.g. developing new skills), frugality (e.g. pursuing resourcefulness), community participation and opportunities for meaningful action to be intrinsically satisfying and durable motivators of long-term environmental stewardship (De Young 1996; Ryan and Grese 2005; Ryan et al. 2001). Furthermore, and most relevant to the issue at hand, green citizens are revealed to be explorers and problem-solvers (Hamilton et al. 2018). These citizens are engaged in anticipatory adaptation (Lyles 2015; Ryan 2016), a pro-active form of pre-familiarisation, planning and capacity-building (Wamsler et al. 2018). The emerging profile of green citizens suggests a need for interventions that dramatically differ from those aimed at promoting green consumerism (Guckian et al. 2017). However, green citizenship may involve more mentally taxing reflection and planning, an issue returned to shortly.

\subsubsection{Small Experiments}

The new behavioural context includes the stressful conditions of great and prolonged uncertainty, and grave stakes. These are circumstances where we would be advised to start with small steps. As Scott (1998: 345) advises, "Prefer wherever possible to take a small step, stand back, observe, and then plan the next small move". Scott's (1998) idea follows, in part, the 'small experiment' approach to environmental problem solving outlined by Kaplan (1996; see also Irvine and Kaplan 2001; Kaplan et al. 1998).

Small experiments are a framework for supporting problem-solving that is based on people's natural tendency to explore and understand (Kaplan and Kaplan 2003, 
2009) and on their brain having evolved to prospect the future not just track the past (Seligman et al. 2013). The small experiment approach supports behavioural innovation, maintains local relevance and allows for the rapid dissemination of findings. It contrasts with the large-scale approach that dominates research these days, in that it helps non-scientists systematically discover what works in their community. Small experiments are going on all the time. They are often the basis of stories told by gardeners, teachers, do-it-yourself creators and community organisers. They are present when experts and citizens jointly apply their separate talents and knowledge to an issue of mutual concern. Small experiments are so common that they could be mistaken as inconsequential. In fact, they are a powerful means of behavioural experimentation.

\subsubsection{Behavioural Entrepreneurship}

Clearly, the needed interventions change when addressing the new behavioural context. No longer adequate are approaches focused on single and specific behaviours. If this were not challenging enough, even with our current expertise we are unable to know exactly which future behaviours will need promoting. Thus, what we must support is the capacity of future citizens to identify the needed behaviours without our being there. Furthermore, citizens also would need to innovatively execute and maintain those behaviours in that future. Taken together, such capacities constitute entrepreneurial thought, craft and action. In the present, this calls for a unique form of intervention. We need to support behavioural entrepreneurs by creating conditions today under which individuals develop the capacity to anticipate, envision and prospect a future context. Then, when later they are in that context, those individuals will be able to craft innovative responses and self-regulate their behaviour to carry out those responses. The shift here is subtle, and perhaps appears academic, but it is a move away from expert-driven, delivery-based interventions toward the facilitation of citizen-developed interventions occurring in a partially unknowable future context.

This is neither a radical nor an unfamiliar approach although it is rarely used in the current rush to promote behaviour change. It is derived from Lewin's (1952) pioneering work using citizen groups to affect fundamental change by first honestly presenting people with the situation being faced and then giving them the trust, time and support needed to craft their own responses. Programs based on Lewin's approach are being developed to promote environmental stewardship (Fisher and Irvine 2016; Matthies and Kromker 2000) including the community-based initiatives called Ecoteams (Davidson 2011; Nye and Burgess 2008; Staats and Harland 1995; Staats et al. 2004). There are also larger-scale examples including eco-housing and ecovillages (Litfin 2013; Nelson 2018) and transition towns (Hopkins 2008). It is significant that the larger-scale examples were neither initiated nor supported by corporations, governments or major environmental organisations, instead they self- 
initiated. Behavioural entrepreneurship is about self-initiating behaviour change. Yet, whether acting individually or in groups, these entrepreneurs will need the capacity to envision, craft and then initiate responses all while functioning within a radically changed context.

\subsection{Capacities-First Approach}

Given that today we cannot fully know the behaviour patterns needed later this century, we must instead ask what are the conditions under which future citizens can respond with competence and equipoise. There is an innovative means of extracting these conditions. It employs a method used within psychological discussions of intentionality (Baumeister et al. 2011; Mele 2001) and is referred to as a capacitiesfirst approach (Seligman et al. 2013). This approach is a form of envisioning (Meadows 1996) and is wholly unlike our current tendency to construct interventions that are primarily past-driven.

A past-driven approach is a leveraging of traits, decision-making tendencies, knowledge, norms and motives from people's immediate and distant past. For instance, we assess whether an individual holds an eco-centric, ego-centric or social-centric value orientation and then create an intervention that leverages their dominant orientation. Another example starts with individuals who are inclined toward a specific environmental stewardship behaviour but lack the necessary procedural knowledge to carry out that behaviour. The intervention would then focus on providing the needed behavioural skills and strategies. A third example is making more salient an existing social norm using a public service announcement. In each instance, we, the experts, assume the role of creating interventions that manipulate existing factors to promote conservation behaviours among citizens.

In contrast, a capacities-first approach is future-centric. Citizens are imagined as actively coping with the challenges in that future context having successfully recast their behaviours into forms that fit that future ecological situation. Perhaps most significant, these future citizens are in no particular need of expert designed and managed interventions. However, perhaps we, the experts, could be of some help in the present. Although we cannot assume to know the specific future behaviours that citizens will be pursuing, we may assume that how they go about identifying and self-initiating those behaviours will be much the same as they do today. They will be using the same mental processes, cope with the same social challenges, be affected by the same emotions and need to develop skills well matched to the future context. Therefore, employing a reverse-engineering metaphor, we can imagine, in the present, what general capacities those future citizens must be in possession of, and the support they will come to rely upon while creating and initiating specific future behaviours. Providing for the development of those capacities now and supporting them in the future becomes a necessary, although perhaps not a sufficient, pre-condition for supporting future sustainability. 


\subsubsection{Needed Future Capacities}

Applied here, this approach involves identifying the capacities that would be needed in order for citizens to plan, self-initiate and regulate their behaviour. A complete list of such capacities and their functional relationships would be long, drawing from the full range of social science research. For the purpose here, we can bound the list by considering only those features needed for conducting the mental work of envisioning, crafting and implementing behaviours in a future context.

Hertwig and Grüne-Yanoff (2017), in their explanation of the advantage of using boosting rather than nudging to change behaviour, mention creating competencies that are useful across a range of situations including, presumably, those for which we cannot in advance know the details. Their discussion of these capacities includes improving people's competencies to exercise their own agency. One example is the authors distinguishing between short- and long-term boosts with the latter focused on creating generic problem-solving capacities that would be useful in future situations (Sunstein 2016).

Wamsler et al. (2018) are more specific in their discussion of the relationship between mindfulness and sustainability. They highlight such individual capacities as being able to maintain an adaptive and flexible response to events, the minimising of impulsive and habitual reactions and similar self-regulation skills. Analogous capabilities were uncovered in the study of green citizenship (Hamilton et al. 2018) where participants identified the importance of a capacity for openness in approaching a situation so as to avoid habitual response. Green citizens also seek opportunities to learn new skills while simultaneously deriving intrinsic satisfaction from these same opportunities (Guckian et al. 2017; Hamilton et al. 2018).

These ideas suggest a preliminary set of three capacities necessary for effectively responding to the new biophysical and behavioural context.

Mental Clarity Clear-headedness would be necessary for envisioning desired future states. Conscious deliberation and reflection are needed to plan the intermediate and long-term goals, and relevant behaviours, needed for achieving those future states.

Building Competencies Given that future behaviours are unknowable in their details there is the need for a motivation to continuously develop new competencies rather than merely the training of specific skills. Particularly important is the ability to understand diverse and complex social and natural systems in order to be able to identify intended and unintended consequences of future actions.

Emotional Regulation The premise of this chapter cannot help but be unsettling. Nonetheless, given the likely need for social coordination, it will be necessary to maintain pro-social inclinations under the stress of difficult biophysical circumstances. Maintaining a positive emotional state will help to build and maintain social and behavioural resources. 


\subsubsection{Supporting Capacity Building}

As disparate as the aforementioned capacities for clarity, competence building and emotional stability may seem at first, they share a common foundation: the ability to maintain attentional vitality (Basu 2015). Mental clear-headedness is a precondition for human effectiveness (Kaplan 1995) and thus vital to behavioural entrepreneurship. Envisioning future situations and, more importantly, imagining groups of behaviours that need to be adopted together for an effective response will need to be done while in the presence of the radically changing biophysical and behavioural contexts outlined above, the desperate needs of others and unmet personal needs.

It is here that the enormous adaptive significance of mental vitality becomes clear. It allows for pausing to insert our own intentions between the demands of the immediate environment and the future for which we are seeking to prepare a response (De Young 2010). With this ability, future citizens could envision multiple futures without undue confusion, contemplate alternate priorities and explore alternatives instead of jumping to first conclusions. In addition, and most relevant here, it allows imagining which combinations of behavioural responses will work well together. The importance of this ability cannot be overstated. Without this ability, future citizens could not override automatic functioning whether based on innate stimulus-driven patterns (e.g. inherited inclinations) or learned patterns (e.g. habitual responses). In short, the entrepreneurial thought, craft and action needed to respond well will depend on citizens maintaining their mental vitality.

Yet, preserving mental vitality is difficult even in the best of times since handling all the information we crave, as well as dealing with the onslaught of unbidden information, easily leads to our being overwhelmed and mentally exhausted. The challenge is all the more formidable under the premise of this chapter. Yet, while the cognitive demands placed on behavioural entrepreneurs will certainly tax their mental well-being, research has repeatedly highlighted the restorative effect of time spent in natural settings (see Marselle Chap. 7, this volume; Marselle et al. Chap. 9, this volume; Kaplan and Berman 2010; Kaplan and Kaplan 2009). This leads to a fascinating, if somewhat counterintuitive, aspect of the new biophysical context. It is possible that life will become less affluent, less easily mobile and less consumerbased. At the same time, everyday life may become more locally oriented with everyone more involved in their own provisioning. Thus, slowly over time, daily access to nearby nature may increase. Given that such access can improve mental, physical, social and spiritual well-being (see Cook et al. Chap. 11, this volume; Irvine et al. Chap. 10, this volume), the very restoration needed to effectively respond to the new context will be available within that same context.

Mental vitality is a state-of-mind essential to entrepreneurial behaviour but there is also a need for citizens to derive a motive from such engagement. Fortunately, the motives necessary to support behavioural entrepreneurship are embedded in the very challenges involved and are well-studied. It turns out that humans are intrinsically motivated to pursue capacity building (De Young 1996, 2000; Howell 2013; O'Brien and Wolf 2010; Sheldon et al. 2011; Van der Werff et al. 2013). Chawla 
(1998) found that environmentally involved individuals credit intrinsic motivation when explaining the development of competence in both responding to difficulties and interacting effectively with others. There are also intrinsic satisfactions embedded in the pursuit of green citizenship (Guckian et al. 2017; Hamilton et al. 2018; Wolf 2011). It is indeed fortunate that people are able to derive a deep and direct intrinsic motivation from those behaviours that will need to be commonplace in the future.

There is a fascinating technique for focusing people's attention on the future by increasing their psychological connectedness to their future self (Schelling 1984). Zaval et al. (2015) were able to increase this connection by having participants write a brief essay about how they wished to be remembered. Envisioning their legacy had the effect of helping people to have a much longer time-horizon and be intrinsically motivated to pursue environmental stewardship behaviours.

Another means of helping people to develop future-oriented competencies is offered by Fredrickson's Broaden and Build model (1998). This model identifies the behavioural benefits of maintaining a positive emotional state. Fredrickson explored the paradox that while negative emotions are linked to specific action tendencies (e.g. anger promotes urge to attack, guilt leads to desire to make amends) there are no specific behaviours linked to positive emotions. Negative emotions also are known to greatly narrow the scope of attention, the information considered and the capacity for reflection. In contrast, positive emotional states expand cognition; inspire creativity, exploration and the development of future behavioural options. This has the effect of expanding our repertoire of behavioural responses. Fredrickson describes the broadening effect as widening the scope of thoughts that come to mind, and the building effect as increasing the resources available for responding (e.g. new plans, strategies, social relationships). Although positive emotional states are transitory, the physical, intellectual and social competencies, and resources built endure.

\subsection{Conclusion}

After having supported the capacity building of future behavioural entrepreneurs, we might imagine how their behaviour change strategies would develop. One vision has them analytically and rationally creating technically efficient responses to the new contexts and then adopting behaviours in well-organised packages having the highest environmental impact. A second vision imagines citizen-artists who have elegantly crafted lives functioning harmoniously within a diverse social community and vibrant natural environment with patterns of behaviour evolving and interacting beautifully. In the latter vision the slowly adapting structure of everyday life would comprise a behavioural aesthetic resulting in great contentment and sense of accomplishment.

These two visions of how behaviour change efforts may unfold are not mutually exclusive. Indeed, a mixture of the two seems plausible within a given community and across time. However, the second vision is much less common among experts 
who focus on changing people's conservation behaviour. Thus, providing support for this second vision seems a useful place to conclude. It turns out that the second vision, like behavioural entrepreneurship, is neither a radical nor an unfamiliar approach to environmental stewardship.

\subsubsection{Conservation Aesthetic}

Aldo Leopold (1933) is remembered for his promotion of a conservation and land ethic. However, near the end of his book, A Sand County Almanac (1949), he introduced the idea that the planet also could be restored using a conservation aesthetic. The distinction between these approaches to behaviour change is dramatic. A land ethic, whether voluntary or mandatory, involves "a limitation on freedom of action in the struggle for existence" (Leopold 1949: 202), an obligation to exercise restraint. In contrast, a conservation aesthetic would have us seek interactions with nature because we derive satisfaction from them. A conservation aesthetic is revitalising, unleashing pleasures derived from the hidden riches of interacting directly with the biodiversity of nature.

\subsubsection{Behavioural Aesthetic}

Modern industrial society rejoices in its many technical efficiencies and innovations. However, these accomplishments are challenged by new data (Bonaiuti 2017). What seems efficient from one perspective is brittle from another. Material production and consumption on a global scale turns out to require complex systems and demand massive energy inputs. This leads to increasing economic and social system vulnerabilities as the complexity reaches diminishing marginal returns (Tainter 1988) and as the production of natural resources both becomes less predictable and suffers from declining energy surpluses. Furthermore, focusing on the output from this vulnerable complex system reveals that consumer consumption, the end goal of the entire enterprise, is an astonishingly inefficient means of providing for social and spiritual well-being (De Young and Princen 2012; Kasser 2009; Kjell 2011; O’Brien 2008).

Critiques of modernity are not new. Nevertheless, there is a new claim that industrialisation destroys the aesthetic quality of everyday life. Berry (1987: 165-166) has made this observation about what one gains from daily work in non-industrial enterprises. He cites the work of Gill (1983: 65) on the higher calling that working manually fulfills, "...every [one] is called to give love to the work of [their] hands. Every [one] is called to be an artist". Berry makes this same claim throughout his poetry, fiction and non-fiction writing, frequently offering up small-scale agriculture as an instance of an artistic enterprise involving multiple and overlapping daily decisions centered on the concepts of beauty, resourcefulness and feeding of spiritual 
well-being as much as the body. Perhaps, as we endeavor to first repair and then maintain the planet, everyone will be called upon to be an artist, an idea consistent with Seligman's (1999) notion that authentic happiness comes from "living life as a work of art".

Thus, we have an idea, previously applied to agrarian pursuits but perhaps applicable to everyday enterprise, that would have us seek an aesthetic outcome to the behaviours we pursue. In addition to the environmental impact notion mentioned earlier, this current idea would involve selecting behaviours that, when they are considered in the whole, constitute something of beauty that enhances mental, social and spiritual well-being. This idea would have citizens weave together desired and valued outcomes matched to environmental stewardship goals, the use of old and the learning of new skills with all being adjusted through reflection and equipoise. The term behavioural aesthetic captures both the ongoing process and most certainly the outcome achieved across time; this is a form of performance art but at the everyday level and focused on sustainability.

\section{References}

Alexander S (2011) The voluntary simplicity movement: reimagining the good life beyond consumer culture. University of Melbourne, Melbourne Australia. https://doi.org/10.2139/ ssrn.1970056. Accessed 21 June 2018

Bardi U (2011) The limits to growth revisited. Springer, London

Bardi U (2014) Extracted: how the quest for mineral wealth is plundering the planet. Chelsea Green Publishing, White River Junction

Basu A (2015) Bringing out the best in ourselves. In: Kaplan R, Basu A (eds) Fostering reasonableness. Maize Books, Ann Arbor, pp 87-104

Baumeister RF, Crescioni A, Alquist J (2011) Free will as advanced action control for human social life and culture. Neuroethics 4:1-11

Berry W (1987) Home economics. North Point Press, San Francisco

Bonaiuti M (2017) Are we entering the age of involuntary degrowth? promethean technologies and declining returns of innovation. J Clean Prod. https://doi.org/10.1016/j.jclepro.2017.02.196

Chawla L (1998) Significant life experiences revisited: a review of research on sources of environmental sensitivity. Environ Educ Res 4:369-382

Clayton S (ed) (2012) The Oxford handbook of environmental and conservation psychology. Oxford University Press, New York

Clayton S, Devine-Wright P, Stern PC, Whitmarsh L, Carrico A, Steg L, Swim J, Bonnes M (2015) Psychological research and global climate change. Nat Clim Chang 5:640-646

Cleveland CJ (2005) Net energy from the extraction of oil and gas in the United States. Energy 30:769-782

Cleveland CJ, Costanza R, Hall CAS, Kaufman R (1984) Energy and the US economy: a biophysical perspective. Science 225:890-897

Daly HE, Farley J (2010) Ecological economics: principles and applications. Island Press, Washington, DC

Davidson S (2011) Up-scaling social behaviour change programs: the case of EcoTeams. In: Whitmarsh L, O'Neill S, Lorenzoni I (eds) Engaging the public with climate change: behaviour change and communication. Earthscan, Washington, DC, pp 180-199

De Young R (1996) Some psychological aspects of reduced consumption behaviour: the role of intrinsic satisfaction and competence motivation. Environ Behav 28:358-409 
De Young R (2000) Expanding and evaluating motives for environmentally responsible behaviour. J Soc Issues 56:509-526

De Young R (2010) Restoring mental vitality in an endangered world: reflections on the benefits of walking. Ecopsychology 2:13-22

De Young R (2014) Some behavioural aspects of energy descent: how a biophysical psychology might help people transition through the lean times ahead. Front Psychol 5:1255

De Young R, Princen T (2012) The localization reader: adapting to the coming downshift. The MIT Press, Cambridge, MA

Dietz T, Rosa EA, York R (2007) Driving the human ecological footprint. Front Ecol Environ 5:13-18

Dietz T, Gardner G, Gilligan J, Stern P, Vandenbergh M (2009) Household actions can provide a behavioural wedge to rapidly reduce US carbon emissions. Proc Natl Acad Sci 106:18452-18456

Fagnart JF, Germain M (2016) Net energy ratio, EROEI and the macroeconomy. Struct Chang Econ Dyn 37:121-126

Fisher J, Irvine KN (2016) Reducing energy use and carbon emissions: a critical assessment of small-group interventions. Energies 9:172

Fredrickson BL (1998) What good are positive emotions? Rev Gen Psychol 2:300-319

Gardner G, Stern P (2002) Environmental problems and human behaviour, 2nd edn. Pearson, Boston MA

Geller ES, Winett R, Everett P (1982) Preserving the environment: new strategies for behavioural change. Pergamon Press, New York

Gill E (1983) A holy tradition of working. Golgonooza Press, Suffolk

Greer JM (2008) The long descent: a user's guide to the end of the industrial age. New Society Publishers, Gabriola Island

Guckian ML, De Young R, Harbo S (2017) Beyond green consumerism: uncovering the motivations of green citizenship. Michigan J Sustain 5:73-94

Guilford MC, Hall CAS, O’Connor P, Cleveland CJ (2011) A new long term assessment of energy return on investment (EROI) for U.S. oil and gas discovery and production. Sustainability 3:1866-1877

Hall CAS (2011) Introduction to special issue on new studies in EROI. Sustainability 3:1773-1777

Hall CAS (2012) Energy return on investment. In: Butler T, Lerch D, Wuerthner G (eds) The energy reader: overdevelopment and the delusion of endless growth. The Foundation for Deep Ecology, Sausalito, pp 62-68

Hall CA (2017) The history, future, and implications of EROI for society. In: Energy return on investment: a unifying principle for biology, economics, and sustainability. Springer, Cham, pp 145-169

Hall CAS, Day JW (2009) Revisiting the limits to growth after peak oil. Am Sci 97:230-237

Hall CAS, Klitgaard KA (2011) Energy and the wealth of nations: understanding the biophysical economy. Springer, New York

Hall CAS, Balogh S, Murphy DJR (2009) What Is the minimum EROEI that a sustainable society must have? Energies 2:25-47

Hamann K, Baumann A, Loschinger D (2016) Psychology of environmental protection: handbook for encouraging sustainable action. http://www.wandel-werk.org/docs/20171007-Handbook_ english.pdf. Accessed 21 June 2018

Hamilton EM, Guckian ML, De Young R (2018) Living well and living green: participant conceptualizations of green citizenship. In: Leal W, Callewaert J (eds) Handbook of sustainability and social science research, World sustainability series. Springer, Cham, pp 315-334

Hansen J et al (2017) Young people's burden: requirement of negative CO2 emissions. Earth Syst Dynam 8:577-616

Heinberg R, Fridley D (2016) Our renewable future. Post Carbon Institute, Island Press, Washington, DC

Herring SC, Christidis N, Hoell A, Kossin JP, Schreck CJ III, Stott PA (eds) (2018) Explaining extreme events of 2016 from a climate perspective. Bull Am Meteor Soc 99:S1-S157 
Hertwig R, Grüne-Yanoff T (2017) Nudging and boosting: steering or empowering good decisions. Perspect Psychol Sci 12:973-986

Hopkins R (2008) The transition handbook: from oil dependency to local resilience. Chelsea Green Publishing, White River Junction

Howell RA (2013) It's not (just) "the environment, stupid!" values, motivations, and routes to engagement of people adopting lower-carbon lifestyles. Glob Environ Chang 23:281-290

IPCC (2014) Summary for policymakers. In: Climate change 2014: impacts, adaptation, and vulnerability. Part A: global and sectoral aspects. Contribution of working group II to the fifth assessment report of the Intergovernmental Panel on Climate Change. Cambridge University Press, Cambridge/New York

Irvine KN, Kaplan S (2001) Coping with change: the small experiment as a strategic approach to environmental sustainability. Environ Manag 28:713-725

Jackson T (2009) Prosperity without growth: the transition to a sustainable economy. Sustainable Development Commission, London

Jackson T, Webster R (2016) Limits revisited: a review of the limits to growth debate. (Report) London: All-Party Parliamentary Group on Limits to Growth. http://limits2growth.org.uk/ revisited. Accessed 21 June 2018

Kaplan S (1995) The restorative benefits of nature: toward an integrative framework. J Environ Psychol 15:169-182

Kaplan R (1996) The small experiment: achieving more with less. In: Nasar JL, Brown BB (eds) Public and private places. Environmental Design Research Association, Edmond, pp 170-174

Kaplan S, Berman M (2010) Directed attention as a common resource for executive functioning and self-regulation. Perspect Psychol Sci 5:43-57

Kaplan S, Kaplan R (2003) Health, supportive environments, and the reasonable person model. Am J Public Health 93:1484-1489

Kaplan S, Kaplan R (2009) Creating a larger role for environmental psychology: the Reasonable Person Model as an integrative framework. J Environ Psychol 29:329-339

Kaplan R, Kaplan S, Ryan RL (1998) With people in mind: design and management of everyday nature. Island Press, Washington, DC

Kasser T (2009) Psychological need satisfaction, personal well-being, and ecological sustainability. Ecopsychology 1:175-180

Kjell ON (2011) Sustainable well-being: a potential synergy between sustainability and well-being research. Rev Gen Psychol 15:255

Leopold A (1933) The conservation ethic. J For 31:634-643

Leopold A (1949) A Sand County almanac. Oxford University Press, Cambridge

Lewin K (1952) Group decision and social change. In: Swanson E, Newcomb TM, Hartley EL (eds) Readings in social psychology. Holt, New York, pp 459-473

Litfin KT (2013) Ecovillages: lessons for sustainable community. Polity Press, Cambridge

Lyles W (2015) Compassion building practices to improve hazard mitigation and climate adaptation planning. Paper presented at the Association of collegiate schools of planning conference, Houston TX, USA

Matthies E, Kromker D (2000) Participatory planning: a heuristic for adjusting interventions to the context. J Environ Psychol 20:65-74

McKibben B (2010) Eaarth: Making a life on a tough new planet. Times Books, New York

Meadows DH (1996) Envisioning a sustainable world. In: Costanza R, Segura O, Martinez-Alier J (eds) Getting down to earth: practical applications of ecological economics. Island Press, Washington, DC

Meadows DH, Meadows DL, Randers J, Behrens WW (1972) Limits to growth. Potomac Associates, Washington, DC

Meadows DH, Randers J, Meadows DL (2004) Limits to growth: the 30-year update. Chelsea Green Publishing, White River Junction

Mele AR (2001) Autonomous agents: from self-control to autonomy. Oxford University Press, New York 
Monbiot G (2015) Consume more, conserve more: sorry, but we just can't do both, The Guardian. http://www.theguardian.com/commentisfree/2015/nov/24/consume-conserve-economicgrowth-sustainability. Accessed 21 June 2018

Moore HE, Boldero J (2017) Designing interventions that last: a classification of environmental behaviours in relation to the activities, costs, and effort involved for adoption and maintenance. Front Psychol 8:1874

Morgan T (2016) Life after growth. Harriman House, Hampshire

Murphy DJ (2014) The implications of the declining energy return on investment of oil production. Phil Trans R Soc A 372:20130126

Nelson A (2018) Small is necessary: shared living on a shared planet. Pluto Press, London

Nilsson A, Bergquist M, Schultz WP (2017) Spillover effects in environmental behaviours, across time and context: a review and research agenda. Environ Educ Res 23:573-589

Nye M, Burgess J (2008) Promoting durable change in household waste and energy use behaviour. University of East Anglia, Norwich

O'Brien C (2008) Sustainable happiness: how happiness studies can contribute to a more sustainable future. Can Psychol 49:289-295

O'Brien KL, Wolf J (2010) A values-based approach to vulnerability and adaptation to climate change. Wiley Interdiscip Rev Clim Chang 1:232-242

Odum HT (1973) Energy, ecology and economics. Ambio 2:220-227

Princen T (2010) Consumer sovereignty, heroic sacrifice: two insidious concepts in an endlessly expansionist economy. In: Maniates M, Myers J (eds) The environmental politics of sacrifice. The MIT Press, Cambridge, MA, pp 45-164

Princen T (2014) The politics of urgent transition. In: Wolinsky Y (ed) U.S. Climate change policy and civic society. CQ Press, Washington, DC, pp 218-238

Princen T, Maniates M, Conca K (eds) (2002) Confronting consumption. The MIT Press, Cambridge, MA

Rees WE (2010) The human nature of unsustainability. In: Heinberg R, Lerch D (eds) The Post carbon reader: managing the 21st century's sustainability crises. Watershed Media, Healdsburg, pp 194-203

Ryan K (2016) Incorporating emotional geography into climate change research: a case study in Londonderry, Vermont, USA. Emot Space Soc 19:5-12

Ryan RL, Grese RE (2005) Urban volunteers and the environment: forest and prairie restoration. In: Bartlett PF (ed) Urban place. The MIT Press, Cambridge, MA

Ryan RL, Kaplan R, Grese RE (2001) Predicting volunteer commitment in environmental stewardship programs. J Environ Plan Manag 44:629-648

Schelling TC (1984) Self-command in practice, in policy, and in a theory of rational choice. Am Econ Rev 74:1-11

Scott JC (1998) Seeing like a state: how certain schemes to improve the human condition have failed. Yale University Press, New Haven

Seligman MEP (1999) Teaching positive psychology. APA Monit 30:42

Seligman MEP, Railton P, Baumeister RF, Sripada C (2013) Navigating into the future or driven by the past. Perspect Psychol Sci 8:119-141

Sheldon K, Nichols C, Kasser T (2011) Americans recommend smaller ecological footprints when reminded of intrinsic American values of self-expression, family, and generosity. Ecopsychology 3:97-104

Staats H, Harland P (1995) The Ecoteam program in the Netherlands, study 4: a longitudinal study on the effects of the Ecoteam program on environmental behaviour and its psychological backgrounds. Centre for Environmental and Energy Research, Leiden University, Leiden

Staats H, Harland P, Wilke H (2004) Effecting durable change: a team approach to improve environmental behaviour in the household. Environ Behav 36:341-367

Stern PC (2000) Toward a coherent theory of environmentally significant behaviour. J Soc Issues $56: 407-424$

Stern PC (2011) Contributions of psychology to limiting climate change. Am Psychol 66:303-314 
Stern PC, Wolske KS (2017) Limiting climate change: what's most worth doing? Environ Res Lett 12:091001

Sunstein CR (2016) The ethics of influence: government in the age of behavioural science. Cambridge University Press, Cambridge

Tainter JA (1988) The collapse of complex societies. Cambridge University Press, Cambridge

Thaler R, Sunstein CR (2008) Nudge: improving decisions about health, wealth and happiness. Simon and Schuster, New York

Turner G (2008) A comparison of the limits to growth with 30 years of reality. Glob Environ Chang 18:397-411

Turner G (2012) On the cusp of global collapse? updated comparison of the limits to growth with historical data. GAIA 21:116-124

Van der Werff E, Steg L, Keizer K (2013) It is a moral issue: the relationship between environmental self-identity, obligation-based intrinsic motivation and pro-environmental behaviour. Glob Environ Chang 23:1258-1265

Wamsler C, Brossmann J, Hendersson H, Kristjansdottir R, McDonald C, Scarampi P (2018) Mindfulness in sustainability science, practice, and teaching. Sustain Sci 13:143-162

Wolf J (2011) Ecological citizenship as public engagement with climate change. In: Whitmarsh L, O'Neill S, Lorenzoni I (eds) Engaging the public with climate change: behaviour change and communication. Earthscan, Washington, DC, pp 120-137

Wolske KS, Stern PC (2018) Contributions of psychology to limiting climate change: opportunities through consumer behaviour. In: Clayton S, Manning C (eds) Psychology and climate change: human perceptions, impacts, and responses. Elsevier, Amsterdam

Wynes S, Nicholas KA (2017) The climate mitigation gap: education and government recommendations miss the most effective individual actions. Environ Res Lett 12:074024

Zaval L, Markowitz EM, Weber EU (2015) How will I be remembered? conserving the environment for the sake of one's legacy. Psychol Sci 26:231-236

Open Access This chapter is licensed under the terms of the Creative Commons Attribution 4.0 International License (http://creativecommons.org/licenses/by/4.0/), which permits use, sharing, adaptation, distribution and reproduction in any medium or format, as long as you give appropriate credit to the original author(s) and the source, provide a link to the Creative Commons license and indicate if changes were made.

The images or other third party material in this chapter are included in the chapter's Creative Commons license, unless indicated otherwise in a credit line to the material. If material is not included in the chapter's Creative Commons license and your intended use is not permitted by statutory regulation or exceeds the permitted use, you will need to obtain permission directly from the copyright holder.

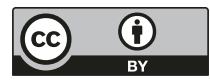

